\title{
FLIGHT ACTIVITIES OF THE ANT DOLICHODERUS (HYPOCLINEA) MARIAE FOREL ${ }^{1}$ \\ By MaRy TALBOT
}

Lindenwood College, St. Charles, Missouri

Often some reference is made to the "flight" of a species of ants as if all the males and females left the colony on one day. W. M. Wheeler, in his 1905 account of the genus Dolichoderus, ${ }^{2}$ said of $D$. mariae: "August 20 is approximately the date of the nuptial flight of this species." Today it is generally understood that there are usually a number of flights. This study shows that $D$. mariae is conspicuous in this respect.

In 1954 a long series of flights of a colony of $D$. mariae was observed at the Edwin S. George Reserve, Livingston County, Michigan. This colony was a large one, which nested in a blackberry patch (Rubus allegheniensis Porter) on a slope facing northwest above Southwest Swamp. The nest had been made by digging out the sandy soil around a blackberry stalk to form a central cavity below ground. Where this was bridged across by roots and stems, great masses of ants rested and placed their brood. Above this they had built a beautifully constructed little igloo, which extended the central cavity aboveground. It was four inches high and seven inches across and was made of dried leaves, small twigs and grass blades, all lightly put together and held in place by the stems which passed through it. Two blackberry stalks and many grass stems (Poa compressa L.) extended above it. Entrances were scattered all over the mound but were inconspicuous be-

${ }^{1}$ The work was assisted by a grant from the Edwin S. George Reserve Scholarship Fund. Facilities of the Reserve were made available by Dr. T. H. Hubbell, Acting Director, and Dr. Irving J. Cantrall, Curator of the Reserve.

${ }^{2}$ Wheeler, W. M., 1905. The North American Ants of the Genus Dolichoderus. Bull. Amer. Mus. Nat. Hist., 21: 305-319. 
cause they were simply openings in the mass of stems and leaves.

The nest was found on August 10, 1954, at 10 o'clock in the morning (Eastern Standard Time), and it was a most interesting sight at that time. The whole mound was completely covered with a milling mass of the vivid red and black workers together with three or four dozen equally bright females. Some workers were foraging, but most seemed to be merely "promenading" in the sun, and a few even carried pupae or larvae about with them. Females seemed to have no urge to climb upward above the mound, and if one started down toward the ground, workers would touch or pull her until she walked up to the top again.

The next day males as well as females were promenading with the workers, and it was suspected that a flight might have taken place earlier that morning. To check this assumption, the colony was observed at 8 a.m. the following day. Although the morning was sunny, the temperature was only $55^{\circ} \mathrm{F}$ and as a result no ants were

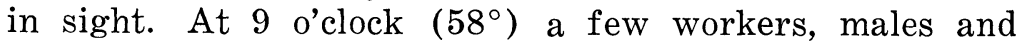
females, were moving slowly on the mound, and by $9: 30$ a.m. $\left(58.5^{\circ}\right)$ some were climbing blackberry and grass stems directly above the nest. Workers were touching some of the winged ants on the side or back in a fashion which caused them to move upward, but most climbed with no urging. Some ants fluttered their wings as they walked about, but none flew until 9:45 a.m. $\left(65^{\circ}\right)$ when four females flew at one time. Many males and females had come from the mound and had climbed upward on blackberries or grasses, but no more flew, for by this time the mound was in partial sunshine and the temperature rose abruptly to $74^{\circ} \mathrm{F}$. By 9:55 a.m. all had come back down, and there was a mass of winged ants and workers on the mound similar to the one seen the day before. Since this does rot constitute a good flight, it is suspected that it was the first of the series.

The flight the next day (August 13) was a typical one with many males and females leaving the colony. At 
8:30 a.m. $\left(60^{\circ}\right)$ the mound was covered with ants, and a steady procession of males and females was climbing above the nest. Again, workers seemed to push some from behind. The first male flew at 8:34 a.m. $\left(61^{\circ}\right)$ and was followed by a continuous stream of others. Females kept fluttering their wings but did not begin to fly until 8:55 a.m. $\left(65^{\circ}\right)$. In the meantime, tops of berry leaves and blades of grass became greatly crowded with the winged ants, males predominating over females. As both continued to fly, there came to be more females then males on the berry bushes, for males stopped coming from the nest before females did. By 9:30 a.m. $\left(66^{\circ}\right)$ the last male had flown and there were no more winged ants on the mound, but females continued to fly from plants until 9:50 a.m. $\left(69^{\circ}\right)$. Toward the end of the flight, workers became active again, but this time they tapped winged ants in such a way that the latter moved downward.

From this day, ants continued to fly each morning unless the weather prevented. Eighteen flights were watched in the 27 days between August 12 and September 7. Bad weather prevented flights on four days, and on five days no observations were made. Perhaps flights began before August 12, and they certainly continued after September 7, when observations ceased, because there were still males and females in the colony.

During this time an amazing number of ants flew. It was hard to count flying ants, but estimates were made for numbers leaving the nest per minute at various times during flying. At least 15,000 flew from the colony. Largest flights occurred on August 20 and 22 and September 1 and 5, when an estimated 1550, 4370, 1750, and 1500 flew. Smallest flights were on August 12 (4), August 17 (33) and August 26 (57). On the latter two days the weather was unfavorable. The flight on September 6 (the last complete one observed) released over 900 ants evidence that numbers had not been greatly depleted at that time.

It soon became apparent that the wide fluctuation of time of day of the flights was determined by temperature 
(Table I). After a cold night flying was delayed, but if the night had been warm it began while the morning light was still dim. Ants were not found outside the nest at $55^{\circ}$ or lower but could walk on the mound at $56^{\circ}$ or $57^{\circ}$. Sometimes they could begin climbing slowly at these temperatures, but usually the migration upward did not start until $59^{\circ}$ was reached. Males and females both climbed at these low temperatures, but at first males greatly

Table I. Temperatures at which flight activities occurred for the ant Dolichoderus mariae Forel. Edwin S. George Reserve, Livingston County, Michigan. 1954.

Range Median

Winged ants began to emerge from nest $56^{\circ}-58^{\circ} \mathrm{F} \quad 57^{\circ} \mathrm{F}$ Winged ants began to climb grasses $56^{\circ}-61^{\circ} \mathrm{F} \quad 59^{\circ} \mathrm{F}$ Beginning of flights

End of flights

$\begin{array}{lll}\text { male } & 58^{\circ}-67^{\circ} \mathrm{F} & 60^{\circ} \mathrm{F} \\ \text { female } & 63^{\circ}-67^{\circ} \mathrm{F} & 64^{\circ} \mathrm{F}\end{array}$

$\begin{array}{lll}\text { male } & 63^{\circ}-71^{\circ} \mathrm{F} & 66^{\circ} \mathrm{F} \\ \text { female } & 67^{\circ}-74^{\circ} \mathrm{F} & 69^{\circ} \mathrm{F}\end{array}$

outnumbered females on the leaves. Fortunately, the position of the nest, on a slope facing northwest, kept it in shade during early morning and allowed temperatures to rise slowly enough so that a difference in the reaction of males and females could be distinguished. Males could begin flying as early as $58^{\circ}$ but they usually waited until the temperature reached $59^{\circ}$ or $60^{\circ}$. Only once did they delay beginning their flight until it was above $64^{\circ}$. That was a morning of dense fog when none flew until $67^{\circ}$. Females never began flying before $63^{\circ}$. When temperatures rose rapidly after a cold night, the two might begin flying at almost the same time, but if temperatures hovered between $58^{\circ}$ and $63^{\circ}$, males might fly for 20 or 30 minutes before females began. One overcast morning there was an exclusively male flight because temperatures never rose above $64^{\circ}$, and all of the females walked back down from the vegetation into the nest. The earliest that males began to fly was $5: 28$ a.m. $\left(67^{\circ}\right)$ and the latest 
was $9: 23$ a.m. $\left(64^{\circ}\right)$. Extremes for beginnings of female flights were 5:30 a.m. $\left(67^{\circ}\right)$ and 10:40 a.m. $\left(64^{\circ}\right)$.

Flights varied greatly in their duration, depending upon how fast the temperature rose. The longest flight lasted from 5:28 a.m. to 8:05 a.m., but it started early in a dense fog, and later, after both males and females were flying, flight was interrupted for an hour because wings became tco wet to be used. One of the shortest flights, lasting 32 minutes, was one of the abundant ones. This occurred on September 1 after two days of bad weather, and an estimated 1750 ants flew. It was a sunny morning and the temperature rose very rapidly from 9:03 a.m. $\left(58.5^{\circ}\right)$ to $9: 35$ a.m. $\left(72^{\circ}\right)$. On this day males flew for 22 minutes from 9:03 a.m. to $9: 25$ a.m. $\left(69^{\circ}\right)$ and females for 21 minutes from $9: 14$ a.m. $\left(63.5^{\circ}\right)$ to $9: 35$ a.m.

The ending of flights varied greatly as to time. Males have stopped flying as early as 6 a.m. or continued as late as 9:45 a.m.; females as early as 6:25 a.m. or as late as 10:45 a.m. Flights could be stopped by rising temperature; no males were seen to fly at temperatures above $71^{\circ}$ nor females above $74^{\circ}$. But often flights ended well below these temperatures. On the four days when the most ants flew, flights stopped at the following temperatures: August 20 - males $64^{\circ}$, females $67^{\circ}$; Augu $t 22$ - males $66^{\circ}$, females $67^{\circ}$; September 1 - males $69^{\circ}$, females $72^{\circ}$; September 5 - males $70^{\circ}$, females $70^{\circ}$. Perhaps on fine mornings all those which were mature flew before the critical temperature was reached. Sometimes practically all those which climbed vegetation flew; yet at other times many returned to the nest. It seems probable that $D$. mariae flights began shortly after the first winged ants emerged from the pupal stage, and flights continued as others emerged. Darkening sky and lowering temperature could end flights, and on these days many males and females returned to the nest.

Flights were prevented on two days by rain, and on two others, apparently, by high winds. On these latter days, males and females were slow about climbing and 
after standing about for a while, returned to the nest even though temperatures were favorable.

Workers took an interesting part in flight. During the first days when females were walking on the mound, workers paid no attention to them unless they tried to walk down off the nest. Soon the urge to go upward became well-developed in males and females, and most of them climbed plants directly above the mound without urging. However, workers climbed grass blades and touched some from behind in such a way that they moved upward. In contrast, when flights were slowing for the day, or when weather became adverse, workers became very active in patrolling grasses and touching, or perhaps biting, males and females in a way that induced them to walk downward. Occasionally a worker carried a male, holding it by the dorsal side of the petiole so that the male was upright and to one side of the carrier. More rarely females would be carried, but usually they were simply "herded" down. Often a great many workers would patrol mound and grasses after a flight. Apparently they did not contact winged ants by sight because, if a male moved out of touch, workers walked about at random until they touched it again. Sometimes workers cooperated three were seen hunting one male, and four worked together to pull a female down a stem. Only once did workers try to prevent a flight. On September 4 at 7 a.m. $\left(59^{\circ}\right)$ for about five minutes, they prevented the males and females from climbing until they pushed their way above the ring of workers on berry stems and grasses and succeeded in having a weak flight.

Spiders profited by flights. On five occasions a spider was seen to capture a male and carry it away, and occasionally a male would fly into a small web attached to grasses near the nest. 

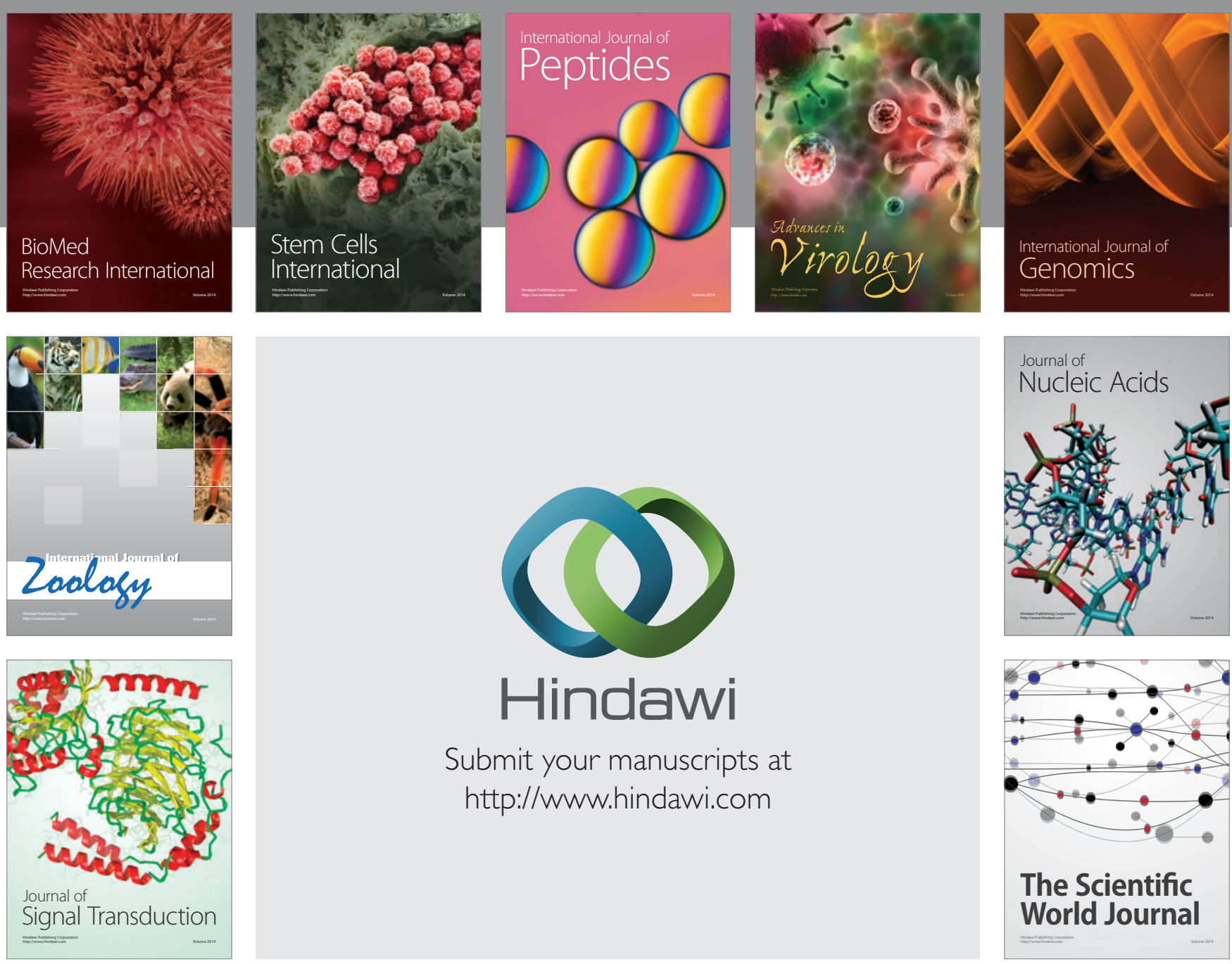

Submit your manuscripts at

http://www.hindawi.com
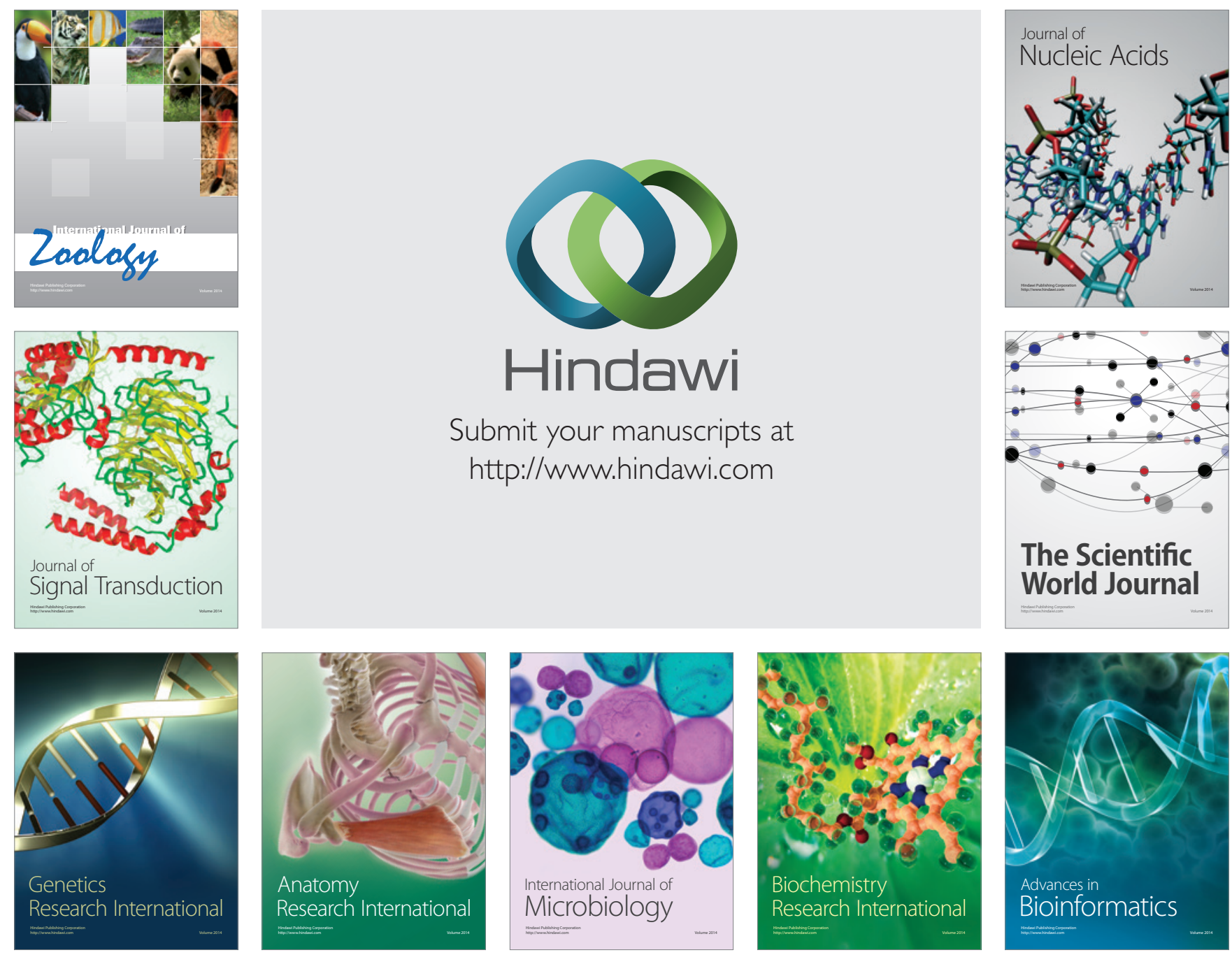

The Scientific World Journal
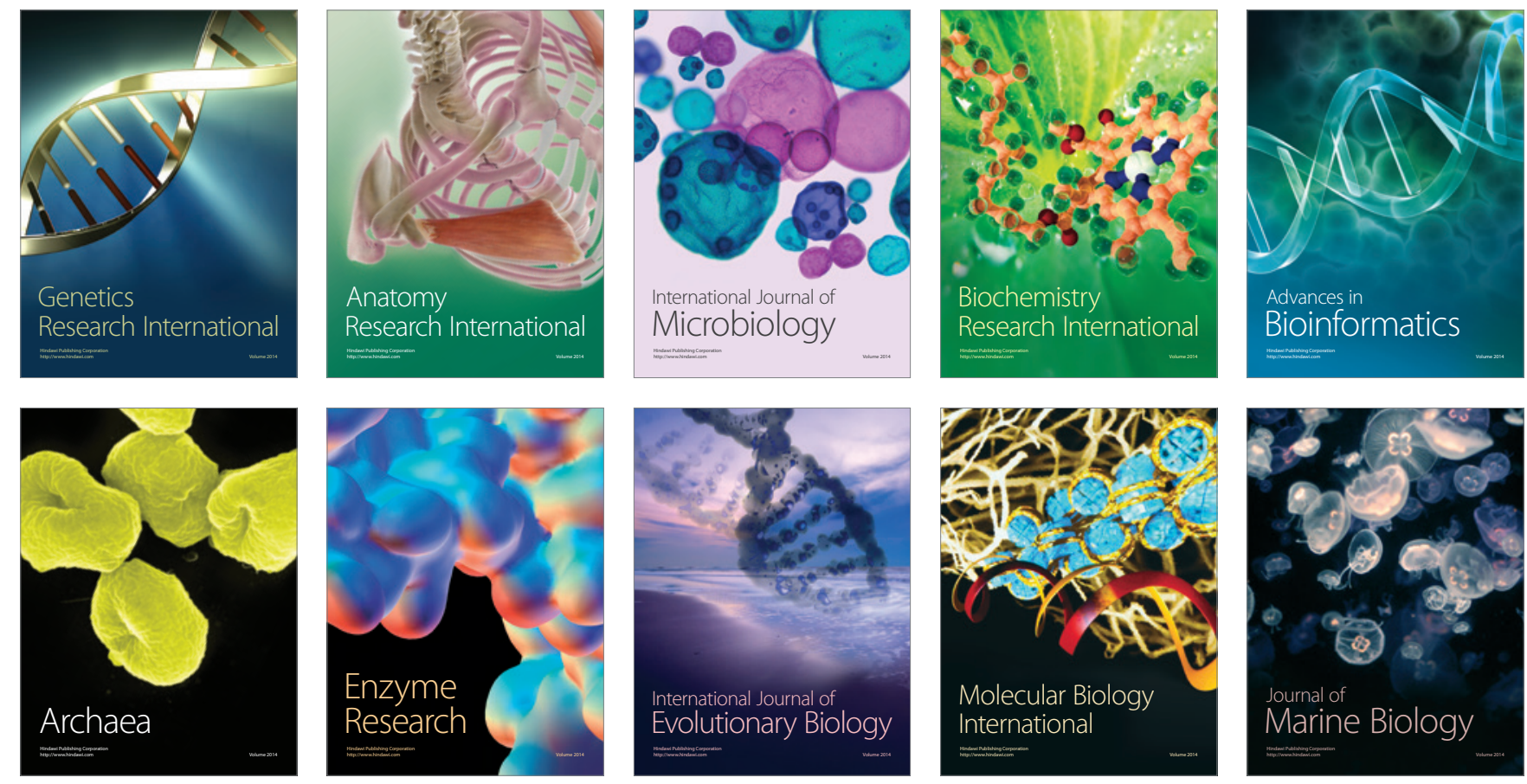